\section{Vegetative roots differ}

Peter D. Moore

Studies on Plant Demography: A Festschrift for John L. Harper. Edited by James White. Academic: 1985. Pp.416. $H b k £ 45, \$ 59.50 ; p b k £ 22, \$ 29.50$.

The Population Structure of Vegetation. Handbook of Vegetation Science, Vol.3. Edited by James White. Dr W. Junk: 1985. Pp.669. Dfl. 310, \$97.50, £85.95.

Throughout the history of plant ecology there have been profound disagreements over the most realistic, or at least the most intellectually profitable, way of studying vegetation. Is vegetation simply a "fortuitous juxtaposition of plant individuals", as maintained by Gleason? Or is it an orderly assemblage of recurrent plant associations, as conceived by certain schools of phytosociology? Plant population biology is essentially the product of an individualistic way of thinking: it is concerned with the interactions between adjacent members of a population, their growth, reproduction and mortality. But the overview of vegetation which the phytosociologist seeks to present must still recognize populations of plants, perhaps co-evolved, as the elemental structures from which higher levels of organization are derived.

Two approaches to the subject are thus possible: we can begin with vegetation and work down towards the individual, or we can begin with the individual in its population and gradually extend towards the more complex interactions of the community. In the books under review we find the two schools of thought effectively and separately illustrated, which is a credit to James White who edited both volumes.

John Harper, to whom the first book is dedicated in celebration of his sixtieth birthday, is rightly regarded as the founding father of plant population biology, and his perspective on the subject is essentially Darwinian and analytical; a view of architecture that begins with the

- R.K. Peet has edited Plant Community Ecology: Papers in Honour of Robert $H$. Whittaker, which contains papers written by Whittaker's past colleagues and students after his death in 1980 . Rather than review Whittaker's own contributions. Peet chose to illustrate current applications of approaches Whittaker developed and to show recent advances which have grown from his pioneering work. The papers are arranged in four sections, representing areas of plant community ecology which were strongly influenced by Whittaker: Methods of community analysis, Analysis of gradients, Community dynamics and Species Diversity. Published by Dr W. Junk as Vol. 7 of the "Advances in Vegetation Science". Pp.332. Dfl. $200 . \$ 68 . £ 55.50$. bricks. This collection of papers by his past students amply demonstrates the value of such an approach. Take John Ogden's work on forests, for example. In this type of habitat the long life-history of the individual gives an impression of stability, but population studies reveal a constant turnover, a mosaic of recovery stages from past disturbances - what Henry Horn has described as a "preemptive crazy quilt" of vegetation.

Mobility, of course, is a special problem for plants, but one that must be overcome if the patchwork of opportunities in the environment is to be fully exploited. Noble illustrates the effectiveness of birds in transporting seeds even when the birds in question cannot fly, as in the case of the gut carriage of Nitraria by emus in Australia.

Turkington, on the other hand, expands on the value of vegetative growth by stolons in clover. Clones can spread extensively in this way (some ecologists even talk of such plants "foraging"), but though the propagation of vegetative clones provides a form of mobility it can lead to a general lack of genetic diversity. In Turkington's view, the input of new genotypes by somatic mutation and occasional germination of new individuals is adequate to provide this required genetic variability.

Studies such as these on clover can lead to confusion about what really constitutes an individual plant. One approach is to consider a plant as a collection of relatively independent units. This idea of modular growth, where each module is the product of a single meristem, is particularly attractive and is exemplified here by Michelle Jones's report of her work on silver birch. In the case of trees, the branching systems differ in their "modular dynamics" because they are influenced by neighbours and respond by the formation of varying crown geometries. The implications of such studies for forestry are further developed by Miguel Franco.

The total collection of papers provides a wide range of examples from current studies in plant population biology. Most of these have originated from Harper's work and ideas, and are now taking root and ramifying.

In The Population Structure of Vegetation, James White is at pains to encourage the recognition of the complementarity of the demographic and sociological approaches. But it is vegetation that is quite recognizably the starting point of most of the papers included here, rather than population studies on individual species. Perhaps the key to the difference in thinking lies in the paper by T.A. Rabotnov on the dynamics of plant coenotic populations. But what, we may be forgiven for asking, is a coenotic population? It is defined as the sum of the individuals of a species within a plant community (the phytocoenosis), and is a concept arrived at by Rabotnov himself (the founding father of the Soviet plant coenotic population biology to whom this book is dedicated) as a result of the mental dissection of vegetation into its interacting components.

One of the consequences of this way of looking at population biology is the need to examine the demography of many different species at the same time; the detailed analysis of one species is of little value in isolation. Inevitably this leads to less-rigorous, less-numerical conclusions than typify the Harper school, but it also encourages the tendency to classify plants according to their interactive "strategies" as a means of simplifying community description. Some interesting proposals have resulted. The threefold classification of plants into "violents", "patients" and "explerents" by Ramenskii, for example, foreshadows the work of Grime, who also summarizes his current views in this volume. But such simple classification systems are not universally adopted by the contributors. Indeed, Grubb provides a detailed argument against the use of such models, demanding a much more critical attitude to the use of such terms as "stress", "tolerance", "dominance", "disturbance" and "competition", and calling for more attention to be given to the factors which permit coexistence among plants.

One prominent aspect of this book are the contributions of Soviet scientists, and Markov's paper on the use of permanent quadrats in the Soviet Union opens up for Westerners a useful window on Eastern ecology. Most of the Soviet papers are concerned with coenotic population research in steppic environments, but more occidental studies are also included, from chalk grasslands in the Netherlands to the cedar groves of the south-eastern United States. There are even some contributions that wander slightly from the "coenotic" theme, such as the demographic study of Plantago major and $P$. lanceolata by van der Aart. But even here the main emphasis is upon the variation in demography according to the plant's habitat - paths, hay fields, dunes, roadsides, pastures and so on - so the community remains the centre of interest.

Perhaps the most remarkable feature to emerge from these two books is the great difference in the starting point and the approach found in each and yet their tendency to generate lines of convergence. These lines will undoubtedly culminate in fruitful fusions, possibly under the diplomatic eye of James White, the sole common factor. Meanwhile, the balanced botanist must obviously have access to both.

Peter D. Moore is Reader in Ecology in the Department of Biology, King's College London $(K Q C), 68$ Half Moon Lane, London SE24 $9 J F, U K$. 